\title{
Urgences
}

\section{Jocelyne Lévesque, Le temps mutilé, Saint-Lambert, Éditions du Noroît, coll. «L'instant d'après», 1991, 72 p.}

\section{Guy Rancourt}

Numéro 34, décembre 1991

Mythes et Romans de l'Amérique

URI : https://id.erudit.org/iderudit/025691ar

DOI : https://doi.org/10.7202/025691ar

Aller au sommaire du numéro

\section{Éditeur(s)}

Urgences

\section{ISSN}

0226-9554 (imprimé)

1927-3924 (numérique)

Découvrir la revue

Citer ce compte rendu

Rancourt, G. (1991). Compte rendu de [Jocelyne Lévesque, Le temps mutilé, Saint-Lambert, Éditions du Noroît, coll. «L'instant d'après», 1991, 72 p.]

Urgences, (34), 125-128. https://doi.org/10.7202/025691ar d'utilisation que vous pouvez consulter en ligne.

https://apropos.erudit.org/fr/usagers/politique-dutilisation/ 


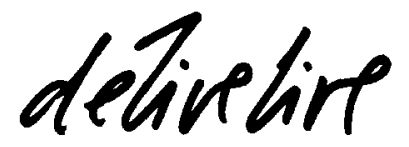

\section{Jocelyne Lévesque, Le temps mutilé, coll. "L'instant d'après", n० 37, Saint-Lambert, Éditions du Noroît, 1991, 72 p.}

Née sous le signe du Verseau à l'aube des années 50 et originaire d'un petit village de la Vallée de la Matapédia, Jocelyne Lévesque enseigne quelques années dans l'Est du Québec. Les années quatre-vingt marquent un tournant chez elle. Après un retour aux études, elle obtiendra ici même à Rimouski (UQAR) des diplômes de baccalauréat et de maîtrise en études littéraires. Son mémoire portait sur Marguerite Duras. Titre exact? Une lecture de Moderato Cantabile de Marguerite Duras: le non-dit narratologique modal et temporel. Et puis, de 1986 à 1988, un court séjour (mais combien fructueux!) à Paris où elle décroche un autre diplôme en littérature française à La Sorbonne (D.E.A.). De retour au pays depuis 1988, Jocelyne Lévesque s'installe à Québec et poursuit des études doctorales en littérature française à l'université Laval tout en étant chargée de cours. Sa thèse de doctorat portera sur un auteur français du vingtième siècle moins connu que Duras; il s'agit de Louis-René des Forêts. Et qui connaît des Forêts à part quelques férus d'écrivains mineurs et de marginaux fuyant tous courants et toutes chapelles littéraires? Des Forêts loge à cette enseigne. Son œuvre est mince. Elle se réduit presque à deux romans publiés dans les années quarante (Les mendiants en 1943 et Le bavard en 1946), un recueil de nouvelles (La chambre des enfants en 1960) et un long poème en alexandrins (Les mémoires de la mer en 1967). Toutefois, c'est Le bavard qui charmera le public français. Des Forêts y fera impitoyablement le procès de la parole et l'expérimentation de son pouvoir magique suscitant de facto l'admiration de Bataille et de Blanchot.

Les pré-textes

Le premier texte "Lumière d'eau " de Jocelyne Lévesque paraît dans Estuaire (numéro 42, automne 1986). Ce texte 
comprend cinq fragments poétiques assez courts (entre cinq et quinze vers) dont le motif est le corps-désir qui semble valser entre deux eaux, entre une larme et un sourire. La poète prend parti pour l'ivresse de vivre et la musique des sens. Le second texte de l'auteure *Fol février", également paru dans Estuaire (numéro 48, printemps 1988), est d'un tout autre registre. On retrouve dans ces neuf brefs fragments (oscillant entre deux et neuf vers) le même motif - le corpsdésir -, mais cette fois-ci luttant contre le temps figé (février) qui secrète son lot de violences et de blessures. Toutes les forces de vie et d'amour qui illuminaient * Lumière d'eau * basculent dans le camp de la mort et de la folie. Pour contrer cette dérive funeste et morbide, la poète dresse le sceptre de la parole et du langage, seule garantie de révolte salvatrice. Jocelyne Lévesque récidive une dernière fois en présentant "Le silence d'écrire" publié dans Mcebius (numéro 45, été 1990). Cette suite poétique rassemble vingt-deux fragments très courts (allant d'un à cinq vers) où le corps-désir est ballotté entre "l'espoir et la désespérance", les "cercueils » et les «berceaux», «la pluie * et * l'étincelle». Toute notre condition humaine se résume chez l'écrivaine à une plaie béante qui débouche soit sur la parole, soit sur le silence. Cela ressemble à la périlleuse entreprise de LouisRené des Forêts dans Le bavard. Comment dire l'indicible? Jocelyne Lévesque joue au funambule qui avance à petit pas au-dessus du brasier des mots et du glacier des silences.

\section{L'couvre: Le temps mutilé}

C'est en 1991 et aux Éditions du Noroît que paraît le premier recueil de poèmes de Jocelyne Lévesque. Le titre? Le temps mutilé publié dans la collection "Linstant d'après». Ce texte est soigneusement illustré de trois encres par Johanne Lévesque (la sœur de Jocelyne). Comment se présente ce recueil? L'aspect formel fort habile rend bien le thème exploité c'est-à-dire celui du temps. Le volume regroupe cent-huit fragments poétiques (et un dernier ayant une fonction particulière) typographiés sur cinquante-quatre pages. Chacune de ces pages contient deux strophes; l'une disposée en haut, l'autre en bas. L'effet recherché par l'auteure est de transposer dans le texte le battement du cœur humain, mesure fragile du temps. 
Donc, temps précaire et toujours en sursis, car, lorsque le cœur s'arrête, le temps est mutilé à tout jamais. Les trois encres de Johanne Lévesque épousent et ligotent bien le thème clé: le temps. Le premier dessin (p. 1) ouvre le recueil sur l'image d'une fleur - une rose -, symbole par excellence de la beauté, mais aussi de l'éphémérité de la vie. Les deux autres dessins montrent des chevaux. Le cheval peut symboliser également le temps qui fuit. Or, le second dessin (p. 29) illustre le combat entre un homme-cheval (la tentative de maitriser le temps) et un cheval (la fuite du temps). Cette lutte semble difficile, laborieuse et mal assurée. Le dernier dessin (p. 49) table encore sur la dualité entre deux chevaux, mais cette fois, l'artiste nous suggère plutôt deux attitudes face au temps. D'abord, nous voyons un cheval qui regimbe et se rebiffe; bref, il s'oppose au temps en essayant de le dominer et de le dompter. L'autre cheval, tout à l'opposé, semble essoufflé, fatigué et résigné. Il courbe l'échine. Il abandonne la lutte et paraît se plier aux rênes du temps. Quelle attitude doit-on choisir face au temps? C'est l'impasse. Peut-on vaincre et mater le temps? Oui et non, nous disent les trois dessins de l'artiste-peintre et les cent-neuf fragments poétiques de l'artiste-poète. Ce débat immémorial est loin d'être clos. Le temps est une plaie ouverte et mal cicatrisée. Le moindre effort peut provoquer l'hémorragie. Qui dit - conscience du temps -, dit conscience de la souffrance; qui dit - conscience du temps - , dit mesure fragile entre linstant et l'éternité. Le dernier vers du recueil $L e$ temps mutilé tente l'ultime résolution du paradoxe: « l'inhumain désordre du désir " (p. 67). Ce vers est à la fois admirable et génial. L'humain est condamné au désordre du désir. Or, le désir est aussi fugitif et insaisissable que le temps. Le désir et le temps sont nos deux chevaux fous: le cheval-désir qui égratigne et exaspère le cœur; le cheval-temps qui tourmente et torture l'esprit. Et que dire du cruel traitement qu'affligent ces deux chevaux tortionnaires à notre pauvre corps! Ce dernier est lacéré et meurtri par l'écartèlement de ces forces contraires. Autre question: peut-on vraiment mutiler le temps? Est-il possible aujourd'hui d'émasculer Kronos comme l'avait fait jadis Zeus? Cela me paraît une entreprise fort hasardeuse, voire vouée à l'échec au point de départ. Jocelyne Lévesque est bien consciente de la difficulté du problème. N'était-ce pas elle qui citait en épigraphe au début de son mémoire sur Marguerite Duras? 
128

Le temps détruit tout ce qu'il crée, et la fin de toute séquence temporelle est, pour l'entité qui y est impliquée, la mort, sous une forme ou une autre. La mort n'est entièrement transcendée que lorsque le temps est transcende; l'immortalité est pour le conscient qui s'est évadé hors du temporel jusque dans l'intemporel. 1

La poète est loin d'avoir épuisé toutes ses ressources. À défaut d'être parvenue à museler le temps, peut-être nous cache-t-elle d'autres surprises ou trouvailles dans le second recueil de poèmes actuellement en chantier?

Guy Rancourt

1 Aldous Huxley, *Quelques réflexions sur le temps " in Les portes de la perception, Paris, Editions du Rocher, 1954, p. 227. 